\title{
Role of CaMKII and PKA in Early Afterdepolarization of Human Ventricular Myocardium Cell: A Computational Model Study
}

\author{
Ling Dai, ${ }^{1}$ Yunliang Zang, ${ }^{1}$ Dingchang Zheng, ${ }^{2}$ Ling Xia, ${ }^{1}$ and Yinglan Gong ${ }^{1}$ \\ ${ }^{1}$ Department of Biomedical Engineering, Zhejiang University, Hangzhou, China \\ ${ }^{2}$ Health and Wellbeing Academy, Faculty of Medical Science, Anglia Ruskin University, Chelmsford CM1 1SQ, UK \\ Correspondence should be addressed to Ling Xia; xialing@zju.edu.cn and Yinglan Gong; yinglangong@zju.edu.cn
}

Received 11 June 2016; Accepted 31 October 2016

Academic Editor: Xiaopeng Zhao

Copyright (c) 2016 Ling Dai et al. This is an open access article distributed under the Creative Commons Attribution License, which permits unrestricted use, distribution, and reproduction in any medium, provided the original work is properly cited.

\begin{abstract}
Early afterdepolarization (EAD) plays an important role in arrhythmogenesis. Many experimental studies have reported that $\mathrm{Ca}^{2+} /$ calmodulin-dependent protein kinase II (CaMKII) and $\beta$-adrenergic signaling pathway are two important regulators. In this study, we developed a modified computational model of human ventricular myocyte to investigate the combined role of CaMKII and $\beta$-adrenergic signaling pathway on the occurrence of EADs. Our simulation results showed that (1) CaMKII overexpression facilitates EADs through the prolongation of late sodium current's $\left(I_{\mathrm{NaL}}\right)$ deactivation progress; (2) the combined effect of CaMKII overexpression and activation of $\beta$-adrenergic signaling pathway further increases the risk of EADs, where EADs could occur at shorter cycle length $(2000 \mathrm{~ms}$ versus $4000 \mathrm{~ms})$ and lower rapid delayed rectifier $\mathrm{K}^{+}$current $\left(I_{\mathrm{Kr}}\right)$ blockage (77\% versus $85 \%)$. In summary, this study computationally demonstrated the combined role of CaMKII and $\beta$-adrenergic signaling pathway on the occurrence of EADs, which could be useful for searching for therapy strategies to treat EADs related arrhythmogenesis.
\end{abstract}

\section{Introduction}

Early afterdepolarizations (EADs) are triggered before the completion of repolarization [1] and associated with polymorphic ventricular tachyarrhythmia for long QT syndrome patients [2]. Prolongation of action potential duration (APD) and recovery of L-type $\mathrm{Ca}^{2+}$ current have been reported as two important factors for the occurrence of EADs [3]. It is also known that the increase of inward currents (e.g., $I_{\mathrm{CaL}}$ and late sodium current, $I_{\mathrm{NaL}}$ ) or the decrease of outward currents (e.g., rapid delayed rectifier $\mathrm{K}^{+}$current, $I_{\mathrm{Kr}}$ and slow delayed rectifier $\mathrm{K}^{+}$current, $I_{\mathrm{Ks}}$ ) at plateau membrane voltage could increase the probability of EADs events. Therefore, any factors that could change the intensity or time sequence of these currents may lead to the occurrence of EADs [4-8].

$\mathrm{Ca}^{2+} /$ calmodulin-dependent protein kinase II (CaMKII) is a key kinase in tuning cardiac excitation-contraction coupling. Its substrates include ion channels, transporters, and accessory proteins [9]. It has been reported that CaMKII phosphorylates $I_{\mathrm{CaL}}$, leading to increased amplitude and
APD prolongation and facilitating the occurrence of EADs $[10,11]$. CaMKII can also alter $I_{\mathrm{NaL}}$, transient outward $\mathrm{K}$ current $\left(I_{\mathrm{to}}\right), \mathrm{SR} \mathrm{Ca}^{2+}$-ATPase (SERCA) [12], and ryanodine receptor (RyR) channels [10]. It would therefore be useful to understand and quantify these regulatory roles. However, it is very difficult for the laboratory experiments to achieve this. Computer modelling approaches provide alternative ways, allowing us to distinguish the most effective phosphorylation target of arrhythmogenesis, which would ultimately provide useful tool in searching for antiarrhythmia therapy.

It has been known that $\beta$-adrenergic signaling pathway regulates $\mathrm{Ca}^{2+}$ cycling partly via phosphorylation of $I_{\mathrm{CaL}}$ and phospholamban (PLB) [13]. $I_{\mathrm{CaL}}$ elevates intracellular $\mathrm{Ca}^{2+}\left([\mathrm{Ca}]_{\mathrm{i}}\right)$ and increases spontaneous $\mathrm{Ca}^{2+}$ release via the SERCA inhibition by PLB. The broken balance of $\mathrm{Ca}^{2+}$ cycling may contribute to the occurrence of EADs [1416]. Volders et al. investigated the ionic mechanisms of $\beta$ adrenergic on the occurrence of EADs in canine ventricular myocyte and concluded that cellular $\mathrm{Ca}^{2+}$ overload and spontaneous SR $\mathrm{Ca}^{2+}$ release played important roles in EADs [17]. 
On the contrary, other studies reported that $\beta$-adrenergic agonists activate protein kinase A (PKA), which phosphorylates $I_{\mathrm{CaL}}$, RyR, PLB, SERCA, and $I_{\mathrm{Ks}}$, resulting in delayed afterdepolarization (DADs) [18]. These numerous targets and different temporal characteristics of phosphorylation effects complicate the mechanism analysis of $\beta$-adrenergic agonists in relation to EADs. Recently, different computational models have been used to investigate these complex interactions. Xie et al. developed a biophysically detailed rabbit model and found that the faster time course of $I_{\mathrm{CaL}}$ versus $I_{\mathrm{Ks}}$ increased ISO-induced transient EADs [19] and emphasized the importance of understanding the nonsteady state of kinetics in meditating $\beta$-adrenergic-induced EADs and arrhythmia. However, other targets including $I_{\mathrm{NaL}}$ have not been investigated thoroughly in their model. It is noted that, although the computational studies of EAD mechanisms have been widely taken, the majority of these published modelling studies have been developed based on nonhuman myocyte. Furthermore, to the best of our knowledge, there is no modelling study considering the combined effect of CaMKII overexpression and $\beta$-adrenergic agonists on EADs.

This study aimed to develop a modified computational model of human ventricular myocyte that integrates CaMKII and $\beta$-adrenergic signaling networks into a modified ORd's dynamic model [20], with which the combined role of CaMKII and $\beta$-adrenergic signaling pathway on the occurrence of EADs would be investigated.

\section{Methods}

2.1. Integration of CaMKII. Since there is a lack of experimental measurements of human ventricle CaMKII pathway, O'Hara et al. used the Hund-Decker-Rudy's dog model to describe CaMKII kinetics $[21,22]$. Our model was developed from the O'Hara-Rudy dynamic model (ORd model) to integrate CaMKII pathway [20]. The following equations describe the CaMKII kinetic of human ventricle:

$$
\begin{aligned}
& \mathrm{CaMK}_{\text {bound }}=\mathrm{CaMK}_{0} \cdot \frac{1-\mathrm{CaMK}_{\text {trap }}}{1+\mathrm{K}_{m \mathrm{CaM}} /\left[\mathrm{Ca}^{2+}\right]_{\mathrm{ss}}} \\
& \mathrm{CaMK}_{\mathrm{active}}=\mathrm{CaMK}_{\text {bound }}+\mathrm{CaMK}_{\text {trap}}, \\
& \frac{d \mathrm{CaMK}_{\text {trap }}}{d t}=\alpha_{\mathrm{CaMK}} \cdot \mathrm{CaMK}_{\text {bound }} \cdot\left(\mathrm{CaMK}_{\text {bound }}+\mathrm{CaMK}_{\text {trap }}\right)-\beta_{\mathrm{CaMK}} \cdot \mathrm{CaMK}_{\text {trap }}, \\
& \alpha_{\mathrm{CaMK}}=0.05 \mathrm{~ms}^{-1}, \beta_{\mathrm{CaMK}}=0.00068 \mathrm{~ms}^{-1}, \mathrm{CaMK}_{0}=0.05, K_{m \mathrm{CaM}}=0.0015 \mathrm{mM} .
\end{aligned}
$$

The fraction of active CaMKII binding sites at equilibrium state $\left(\mathrm{CaMK}_{0}\right)$ was set to 0.05 at the control state. $\mathrm{CaMK}_{0}$ of 0.12 was used to simulate CaMKII overexpression according to the study from Kohlhaas et al. [23].

2.2. Integration of $\beta$-Adrenergic Signaling Networks. The detailed description of $\beta$-adrenergic signaling networks could be found from the published study by Soltis and Saucerman [24]. PKA has been reported to phosphorylate $I_{\mathrm{CaL}}$, PLB, troponin $I$, RyR, myosin binding protein- $C$, protein phosphates Inhibitor- $I$ [25], and $I_{\mathrm{Ks}}$ [24]. $I_{\mathrm{CaL}}, \mathrm{PLB}$, and $I_{\mathrm{Ks}}$ were the three key factors in this study to model the inotropic effect of $\beta$-adrenergic related to potential EADs occurrence. Although the PKA phosphorylation of $\mathrm{Na}^{+} / \mathrm{K}^{+}$ ATPase current $\left(I_{\mathrm{NaK}}\right)$ has been previously described in the computational models $[19,26]$, its effect was not included in this study partially because there is a lack of direct measurements of $I_{\mathrm{NaK}}$ for the normal human ventricle [20]. The phosphorylation by PKA to the three targets $\left(I_{\mathrm{CaL}}, \mathrm{PLB}\right.$, and $I_{\mathrm{Ks}}$ ) is described as follows:

$$
\begin{aligned}
& f_{\text {avail }}=0.017 \cdot \frac{\mathrm{LCC}_{b \mathrm{PKA}_{p}}}{\mathrm{fracLCC}_{b p 0}}+0.983, \\
& \mathrm{dss}=\frac{1}{1.0+\exp (-(V+v \text { shift }) / 4.230)},
\end{aligned}
$$

$$
\begin{aligned}
& I_{\mathrm{CaL}}=\left(\overline{I_{\mathrm{CaL}}} \cdot d \cdot\left(1-\phi_{I_{\mathrm{CaL}, \mathrm{CaMK}}}\right)\right. \\
& \quad \cdot\left(f \cdot(1-n)+f_{\mathrm{Ca}} \cdot n \cdot j_{\mathrm{Ca}}\right)+\overline{I_{\mathrm{CaL}, \mathrm{CaMK}}} \cdot d \\
& \left.\quad \phi_{I_{\mathrm{Ca}, \mathrm{CaMK}}} \cdot\left(f_{\mathrm{CaMK}} \cdot(1-n)+f_{\mathrm{Ca}, \mathrm{CaMK}} \cdot n \cdot j_{\mathrm{Ca}}\right)\right) \\
& \quad \cdot f_{\mathrm{avail}}, \\
& \Phi_{I_{\mathrm{Ca}, \mathrm{CaMK}}}=\frac{1}{1+\mathrm{Km}, \mathrm{CaMK} / \mathrm{CaMK} \text { active }}, \\
& t d=1.2 \cdot(0.6 \\
& \left.\quad+\frac{1}{\exp (-0.05 \cdot(V+6.0))+\exp (0.09 \cdot(V+14.0))}\right) .
\end{aligned}
$$

Equation (2) shows the coefficient that represents the effect of PKA on $I_{\mathrm{CaL}}$ phosphorylation. In (3), the value of " $v$ shift" was increased from 3.94 (no ISO application) to 10.0 (for saturated ISO application), which means that the steady state activation curve of $I_{\mathrm{CaL}}$ was moved left by $6.06 \mathrm{mV}$. The permeability of ion $\mathrm{Ca}^{2+}$ was increased by $10 \%$ with saturated ISO application. Equation (4) describes the augmentation of $I_{\mathrm{CaL}}$ amplitude by multiplying " $f_{\text {avail }}$ " with the value without PKA phosphorylation, and this represents how PKA regulates 
TABLE 1: Current increment and EADs occurrence when different targets were phosphorylated by CaMKII independently.

\begin{tabular}{|c|c|c|c|c|c|}
\hline $\begin{array}{l}\text { Cycle length } \\
(\mathrm{ms})\end{array}$ & $\begin{array}{c}I_{\mathrm{Kr}} \text { blockage } \\
\text { level }(\%)\end{array}$ & $\begin{array}{l}\text { CaMKII target } \\
\left(\mathrm{CaMK}_{0}=0.12\right) \\
\end{array}$ & Target current variation & $\begin{array}{c}\text { Deactivation } \\
\text { time }(\mathrm{ms})\end{array}$ & EADs \\
\hline \multirow{5}{*}{2000} & \multirow{5}{*}{85} & $I_{\mathrm{NaL}}$ & $\begin{array}{c}\text { Decreased by } 24 \% \\
\text { (from } 0.25 \text { to } 0.19 \mu \mathrm{A} / \mu \mathrm{F} \text { ) }\end{array}$ & \multirow[t]{5}{*}{$\begin{array}{l}1297 \text { versus } \\
761 \mathrm{~ms}\end{array}$} & Alternated \\
\hline & & $I_{\mathrm{CaL}}$ & $\begin{array}{c}\text { Increased by } 4.2 \% \\
\text { (from } 1.67 \text { to } 1.74 \mu \mathrm{A} / \mu \mathrm{F} \text { ) }\end{array}$ & & No \\
\hline & & $I_{\mathrm{CaK}}$ & $\begin{array}{c}\text { Increased by } 6.5 \% \\
\text { (from } 0.62 \text { to } 0.66 \mu \mathrm{A} / \mu \mathrm{F} \text { ) }\end{array}$ & & No \\
\hline & & $I_{\mathrm{CaNa}}$ & $\begin{array}{c}\text { Increased by } 8.1 \% \\
\text { (from } 0.37 \text { to } 0.40 \mu \mathrm{A} / \mu \mathrm{F} \text { ) }\end{array}$ & & No \\
\hline & & $I_{\text {to }}$ & $\begin{array}{c}\text { Increased by } 3.2 \% \\
\text { (from } 0.95 \text { to } 0.98 \mu \mathrm{A} / \mu \mathrm{F} \text { ) }\end{array}$ & & No \\
\hline
\end{tabular}

$I_{\mathrm{CaL}}$. In (6), the time constant of activation gate $(t d)$ was extended by $20 \%$ with saturated ISO application

$$
\begin{aligned}
\operatorname{fracI}_{\mathrm{Ksavail}} & =0.49 \cdot \frac{I_{\mathrm{KsPKA}_{P}}}{\operatorname{fracI}_{\mathrm{Ks} p 0}}+0.51, \\
\mathrm{GKs} & =\mathrm{fracI}_{\mathrm{Ksavail}} \cdot \mathrm{GKs}, \\
X s 05 & =11.60 \cdot \mathrm{fracI}_{\mathrm{Ksavail}}, \\
X_{S 1, \infty} & =\frac{1}{1+\exp (-(V+X s 05) / 8.932)} .
\end{aligned}
$$

Equation (7) describes the factor of phosphorylation to $I_{\mathrm{Ks}}$ by $\mathrm{PKA}$, which was used to alter maximum conductance of $I_{\mathrm{Ks}}(\mathrm{GKs})$ in (8). Meanwhile, $I_{\mathrm{Ks}}$ state steady activation curve was adjusted by time dependent gate value through the factor "fracI Ksavail" in (9) and (10).

\subsection{Combination of CaMKII and $\beta$-Adrenergic} Signaling Networks.

$$
\begin{aligned}
& f \mathrm{PKA}_{\mathrm{PLB}}=\left(\frac{\mathrm{PLB}_{-} \mathrm{PKA}_{n}}{\text { fracPKA }_{\mathrm{PLB}_{0}}}\right) \cdot \frac{1}{4}+\frac{3}{4}, \\
& f \mathrm{Jupp}=\frac{1.0}{\left(1.0+\mathrm{K}_{m, \mathrm{CaMK}} \cdot\left(f \mathrm{PKA}_{\mathrm{PLB}} / \mathrm{CaMK}_{\text {active }}\right)\right)}, \\
& \operatorname{Jup}=(1.0-f \mathrm{Jupp}) \cdot \mathrm{Jupnp}+f \mathrm{Jupp} \cdot \mathrm{Jupp}-\text { Jleak. }
\end{aligned}
$$

$\mathrm{CaMK}_{\text {active }}$ that is affected by $\mathrm{CaMK}_{0}$ as shown in (1) would influence $I_{\mathrm{CaL}}$ in (4) via the fraction of $I_{\mathrm{CaL}}$ channels phosphorylated by CaMKII $\left(\Phi_{I_{\mathrm{CaL}, \mathrm{CaMK}}}\right)$. The fraction of SERCAs phosphorylated by CaMKII in (12) was affected by "fPKA $A_{\mathrm{PLB}}$ " and "CaMK $\mathrm{Cactive}$ ", representing the effects of PKA and CaMKII on SERCAs, respectively. As shown in (13), SERCAs were separated into nonphosphorylated populations and CaMKII phosphorylated populations. Therefore, the total $\mathrm{Ca}^{2+}$ uptake via SERCAs was adjusted by these two networks simultaneously.
2.4. Simulation Strategy. In order to determine the potential targets in CaMKII-induced EADs, CaMKII was solely overexpressed by assigning the $\mathrm{CaMK}_{0}$ of 0.12 to specific targets (including $I_{\mathrm{NaL}}, I_{\mathrm{CaL}}, I_{\mathrm{CaK}}, I_{\mathrm{NaCa}}$, and $I_{\mathrm{to}}$ ), respectively, while $\beta$-adrenergic signaling was maintained inactive. Next, CaMKII overexpression was applied with ISO administration. $1 \mu \mathrm{M}$ ISO was applied in this study to simulate its effect on myocyte action potential and ion currents.

The cycle length of $2000 \mathrm{~ms}$ was used in this study since it was closer to normal human beat rhythm than the length of $4000 \mathrm{~ms}$ used in the experiments from Guo et al. [27]. In Guo et al.'s work, EADs appeared with $I_{\mathrm{Kr}}$ blockage of about $85 \%$ [27], which was used for comparison in this study. 500 cycles were performed when the simulation reached steady state. In each individual cycle length, the upper bound of solver step size was set $2 \mathrm{~ms}$.

\section{Results}

\subsection{Effect of CaMKII Overexpression on Ion Currents}

3.1.1. Late Sodium Current $\left(I_{N a L}\right)$. As shown in Table 1 and Figure 1, with the overexpressed $\mathrm{CaMK}_{0}$ value to $I_{\mathrm{NaL}}$ of 0.12 and the normal $\mathrm{CaMK}_{0}$ value of 0.05 to other targets, the alternated EADs occur from our simulation with the cycle length (CL) of $2000 \mathrm{~ms}$ and $I_{\mathrm{Kr}}$ blockage of $85 \%$.

As shown in Figure $1, I_{\mathrm{NaL}}$ amplitudes alternated with overexpressed $\mathrm{CaMK}_{0}$. In beats with EADs, $I_{\mathrm{NaL}}$ amplitude was about $24 \%$ smaller $(0.19 \mu \mathrm{A} / \mu \mathrm{F}$ versus $0.25 \mu \mathrm{A} / \mu \mathrm{F})$ than these with normal $\mathrm{CaMK}_{0}$ value to $I_{\mathrm{NaL}}$ and in beats without EADs, $I_{\mathrm{NaL}}$ amplitude was also reduced by $32 \%(0.17 \mu \mathrm{A} / \mu \mathrm{F}$ versus $0.25 \mu \mathrm{A} / \mu \mathrm{F})$. In Figure $1(\mathrm{~d})$, when EADs occurred, $I_{\mathrm{NaL}}$ deactivated, which was about $168 \%$ of normal beats (1297 ms versus $773 \mathrm{~ms}$ ) and about $170 \%$ of the control situation in Figure 1(b) (1297 ms versus $761 \mathrm{~ms}$ ), indicating that overexpressed CaMKII phosphorylation level of $I_{\mathrm{NaL}}$ reduces its amplitude and prolongs $I_{\mathrm{NaL}}$ deactivation process. Furthermore, the results also indicate that the delayed deactivation of $I_{\mathrm{NaL}}$, rather than its amplitude variation, contributes to the formation of EADs.

3.1.2. L-Type Calcium Current $\left(I_{C a L}\right)$. Similarly, as shown in Table 1, with the overexpressed $\mathrm{CaMK}_{0}$ to $I_{\mathrm{CaL}}$ of 0.12 and 


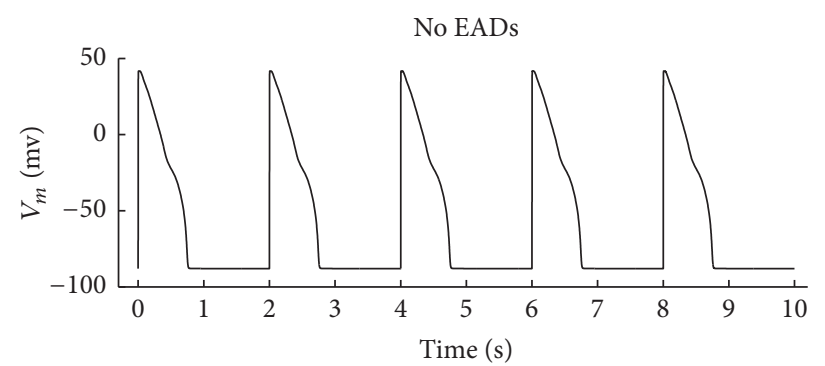

(a)

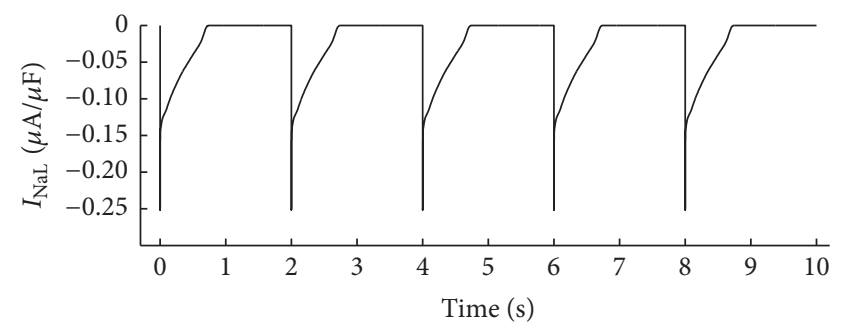

(b)

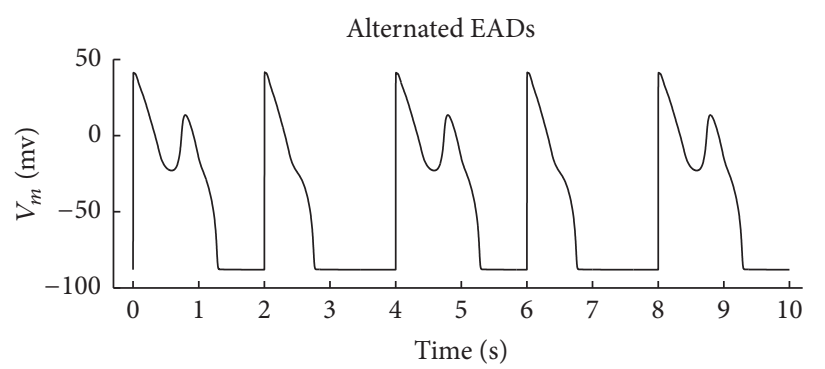

(c)

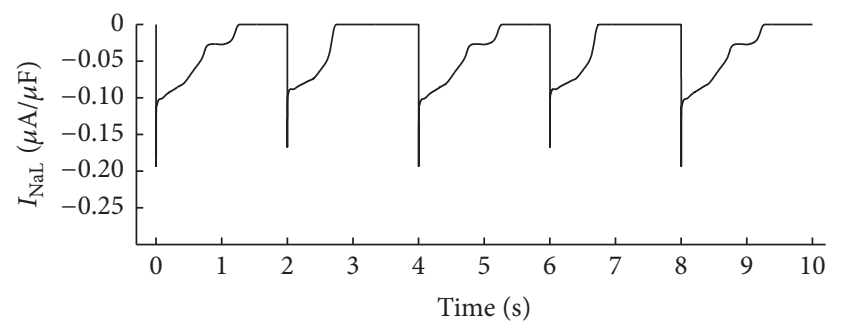

(d)

FIgURE 1: (a) No EAD was produced when CaMKII phosphorylation level was in control $\left(\mathrm{CaMK}_{0}=0.05\right)$. (b) Corresponding $I_{\text {NaL }}$ when no EADs occurred in (a). (c) Alternated EADs were produced when $I_{\mathrm{NaL}}$ phosphorylation by CaMKII was enhanced with CaMK 0 of 0.12 and other targets' phosphorylation levels were in control $\left(\mathrm{CaMK}_{0}=0.05\right)$. (d) Corresponding $I_{\mathrm{NaL}}$ when alternated EADs occurred in (c). Under these conditions, CL was $2000 \mathrm{~ms}$ and $I_{\mathrm{Kr}}$ was blocked by $85 \%$.

TABLE 2: Combined effect of CaMKII overexpression and $\beta$-adrenergic agonist on EADs.

\begin{tabular}{|c|c|c|c|c|}
\hline Cycle length (ms) & ISO application & $\begin{array}{c}\text { CaMKII target }\left(\mathrm{CaMK}_{0}=\right. \\
0.12)\end{array}$ & $I_{\mathrm{Kr}}$ blockage level (\%) & EADs \\
\hline \multirow{7}{*}{2000} & \multirow[t]{3}{*}{ None } & None & 85 & None \\
\hline & & None & 85 & Yes \\
\hline & & None & 77 & No \\
\hline & \multirow[t]{4}{*}{$1 \mu \mathrm{M}$} & $I_{\mathrm{NaL}}$ & 85 & Yes \\
\hline & & $I_{\mathrm{NaL}}$ & 77 & Yes \\
\hline & & $I_{\mathrm{CaL}}$ & 85 & Yes \\
\hline & & $I_{\mathrm{CaL}}$ & 77 & No \\
\hline
\end{tabular}

the normal $\mathrm{CaMK}_{0}$ value of 0.05 to other targets, no EADs occur at CL of $2000 \mathrm{~ms}$ and $I_{\mathrm{Kr}}$ blockage of $85 \%$, suggesting that the probability of EADs might have little relation with amplitude of $I_{\mathrm{CaL}}$. With the enhanced $\mathrm{CaMK}_{0}$ value to $I_{\mathrm{CaL}}$, the amplitudes of $I_{\mathrm{CaL}}$ only increased by $4.2 \%(1.74 \mu \mathrm{A} / \mu \mathrm{F}$ versus $1.67 \mu \mathrm{A} / \mu \mathrm{F})$.

3.1.3. $\mathrm{K}^{+}$Current through the L-Type $\mathrm{Ca}^{2+}$ Channel $\left(I_{\mathrm{CaK}}\right)$, $\mathrm{Na}^{+}$Current through the L-Type $\mathrm{Ca}^{2+}$ Channel $\left(\mathrm{I}_{\mathrm{CaNa}}\right)$, and Transient Outward $\mathrm{K}^{+}$Current $\left(I_{t o}\right)$. As above, CL was set to $2000 \mathrm{~ms}$ and $I_{\mathrm{Kr}}$ was blocked by $85 \%$. As shown in Table 1 , with enhanced CaMKII phosphorylation level $\left(\mathrm{CaMK}_{0}=\right.$ 0.12 ) to different targets, $I_{\mathrm{CaK}}$ increased only by $6.5 \%$ $(0.66 \mu \mathrm{A} / \mu \mathrm{F}$ versus $0.62 \mu \mathrm{A} / \mu \mathrm{F}), I_{\mathrm{CaNa}}$ by $8.1 \%(0.40 \mu \mathrm{A} / \mu \mathrm{F}$ versus $0.37 \mu \mathrm{A} / \mu \mathrm{F})$, and $I_{\text {to }}$ by $3.2 \%(0.98 \mu \mathrm{A} / \mu \mathrm{F}$ versus $0.95 \mu \mathrm{A} / \mu \mathrm{F})$. No EADs occurred under all these conditions.

\subsection{Combined Effect of CaMKII Overexpression and $\beta$-Adrenergic Agonist}

3.2.1. Normal CaMKII and $1 \mu M$ ISO. The action potentials with different $I_{\mathrm{Kr}}$ blockage level are shown in Figure 2. A fixed $\mathrm{CL}=2000 \mathrm{~ms}$ was used and CaMKII phosphorylation level to all targets was kept control $\left(\mathrm{CaMK}_{0}=0.05\right)$. In Figure 2(a), with $I_{\mathrm{Kr}}$ blocked by $85 \%$, stable EADs occurred with the application of ISO, indicating that $\beta$-adrenergic agonist facilitates EADs. The $I_{\mathrm{Kr}}$ blockage level decreased gradually from $85 \%$, and, when it was decreased to $77 \%$, as shown in Figure 2(b), these EADs disappeared, indicating that $77 \%$ was the threshold value for EADs disappearance in this setting. Therefore, $77 \%$ was used in following simulation to compare with previously published level of $85 \%$ [20]. These results are listed from row 2 to row 3 in Table 2. 


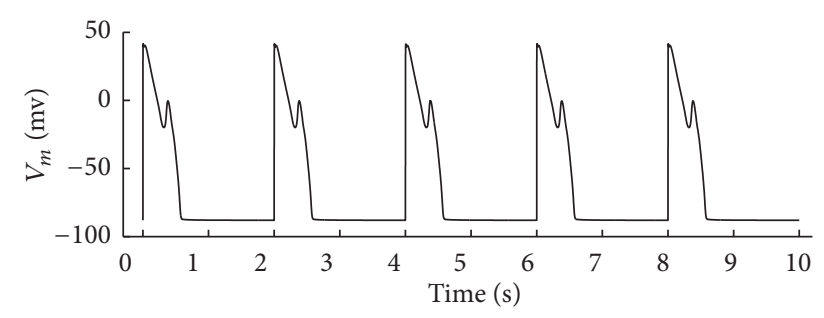

(a)

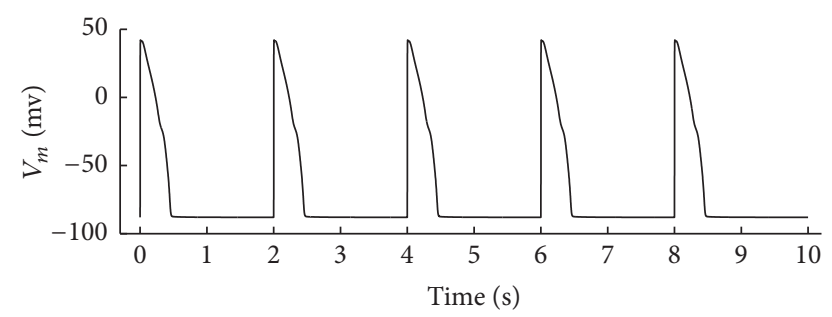

(b)

FIGURE 2: (a) EADs were induced when $1 \mu \mathrm{M}$ ISO was applied and $I_{\mathrm{Kr}}$ was blocked by $85 \%$. In (b), EADs disappeared when $I_{\mathrm{Kr}}$ blockage was reduced to $77 \%$. Cycle length was set $2000 \mathrm{~ms}$ and CaMKII phosphorylation level to all targets was kept control $\left(\mathrm{CaMK}_{0}=0.05\right)$.

3.2.2. Enhanced CaMKII to $I_{N a L}$ and $1 \mu M$ ISO. As shown in Figure 3, with enhanced CaMKII to $I_{\mathrm{NaL}}$ and $1 \mu \mathrm{M}$ ISO, when $I_{\mathrm{Kr}}$ was blocked by $85 \%$, EADs were induced. The EADs were still observed when $I_{\mathrm{Kr}}$ was blocked by $77 \%$, suggesting that $I_{\mathrm{NaL}}$ phosphorylation by CaMKII and ISO application together increased the probability of EADs. These results are listed from row 4 to row 5 in Table 2.

3.2.3. Enhanced CaMKII to $I_{C a L}$ and $1 \mu M$ ISO. As shown in Figure 4, with enhanced CaMKII to $I_{\mathrm{CaL}}$ and $1 \mu \mathrm{M}$ ISO, when $I_{\mathrm{Kr}}$ was blocked by $85 \%$, EADs were induced, but when $I_{\mathrm{Kr}}$ blockage was reduced to $77 \%$, EADs disappeared. These results are listed from row 6 to row 7 in Table 2.

\section{Discussion}

This study developed a modified computational model of human ventricular myocardium cell based on the ORd human model with the integration of regulation mechanism by CaMKII and PKA [20], with which their effects on EADs have been investigated.

EADs often occur during bradycardia under the condition of reduced repolarization reserve. O'Hara's group successfully elicited EADs with cycle length reduced to $4000 \mathrm{~ms}$ and $I_{\mathrm{Kr}}$ blocked by $85 \%$ [20]. In our simulation, with the cycle length halved (2000 ms) and $I_{\mathrm{Kr}}$ blocked by $85 \%$, alternated EADs occurred with the sole effect of CaMKII overexpression to $I_{\mathrm{NaL}}$, suggesting that ventricular myocardial cell with CaMKII overexpression is more susceptible to EADs in normal $\mathrm{HR}$ range $(\mathrm{CL}=2000 \mathrm{~ms})$. Additionally, previous work has shown that $I_{\mathrm{CaL}}$ plays an important role in the occurrence of EADs [6]. Our simulation showed that CaMKII overexpression slightly increased $I_{\mathrm{CaL}}$ amplitude, but this effect alone did not induce EADs, and CaMKII did not alter the overlap region of $I_{\mathrm{CaL}}$ steady state activation and reactivation curves. Zaza et al. reported that [28], when repolarization is suitably slow, channel reactivation within the overlap region may break the current balance and support the possibility of autoregenerative depolarization. Other inward currents such as $\mathrm{Na}^{+}-\mathrm{Ca}^{2+}$ exchange current $\left(I_{\mathrm{NaCa}}\right)$ may play certain roles in triggering EADs if amplitude is augmented and falls into the overlap region. Our simulation results suggest that CaMKII enhances these currents but does not induce EADs via this effect individually. Therefore, when CaMKII is overexpressed, the susceptibility to EADs is mainly originated from $I_{\mathrm{NaL}}$ variation.

Our study also demonstrated the behavior of ventricular myocardial cell with the integration of CaMKII overexpression and ISO application. With the ISO application, cyclic AMP (cAMP) is formed through $\beta$-adrenergic mediated activation of adenylyl cyclase, which activates PKA, a welldescribed mediator with targets that promote myocardial performance. In the case where PKA took effect independently, EADs occurred with shorter cycle length $(2000 \mathrm{~ms}$ versus $4000 \mathrm{~ms}$ ), indicating that the precondition of EADs is relaxed. Our results were different from that from Xie et al.s study, where the APD shortening after ISO application was observed without EADs in steady state [19]. Xie et al's results could be caused by the simulation of transient $I_{\mathrm{CaL}}$ recovery and the prevented spontaneous $\mathrm{SR} \mathrm{Ca}^{2+}$ release, limiting the $I_{\mathrm{NaCa}}$ in forward mode. Therefore, when the cells step into steady state with small inward $I_{\mathrm{NaCa}}$, the shortening of APD could be reasonable. In our work, $\mathrm{SR} \mathrm{Ca}^{2+}$ release was enhanced by $I_{\mathrm{CaL}}$ amplification. With the integration with $I_{\mathrm{Kr}}$ blockage, $I_{\mathrm{NaCa}}$ was more likely to work as inward current, contributing to the prolongation of APD and occurrence of EADs. Additionally, the shortening of APD was also obtained without $I_{\mathrm{Kr}}$ blockage when $\beta$-adrenergic pathway was activated. Simulation results showed that when cycle length was chosen at $500 \mathrm{~ms}, 1000 \mathrm{~ms}, 1500 \mathrm{~ms}, 2000 \mathrm{~ms}$, and $4000 \mathrm{~ms}$, the corresponding APD90 shortening was $31.6 \mathrm{~ms}(233.0$ versus $201.4 \mathrm{~ms}$ ), $30.5 \mathrm{~ms}$ (268.6 versus $238.1 \mathrm{~ms}$ ), $22.3 \mathrm{~ms}$ (282.6 versus $260.3 \mathrm{~ms}$ ), $17.3 \mathrm{~ms}$ (289.1 versus $271.8 \mathrm{~ms}$ ), and $18.6 \mathrm{~ms}$ (305.6 versus $287.0 \mathrm{~ms}$ ). These results were consistent with the experiment measurements from Volders et al. [29]. In the case that CaMKII overexpression acted on $I_{\mathrm{NaL}}$ alone with ISO application, EADs occur at CL $=2000 \mathrm{~ms}$ and $I_{\mathrm{Kr}}$ blockage by $77 \%$, suggesting that the combination of PKA and CaMKII overexpression on $I_{\mathrm{NaL}}$ relaxes the precondition further $\left(I_{\mathrm{Kr}}\right.$ blockage $77 \%$ versus $\left.85 \%\right)$ and increases the probability of EADs. With the CaMKII overexpressed on $I_{\mathrm{CaL}}$ alone, PKA induced EADs occurrence with $85 \% I_{\mathrm{Kr}}$ blockage, not $77 \% I_{\mathrm{Kr}}$ blockage, suggesting that, with the ISO application, $I_{\mathrm{NaL}}$ phosphorylation by CaMKII has more effect on EADs than $I_{\mathrm{CaL}}$. The steady state of $\mathrm{CaMK}_{\text {active }}$ was simulated with and without ISO application when CL = $2000 \mathrm{~ms}$, and their corresponding maximum values were 0.0469 and 0.0421 , respectively. This suggests that CaMKII activation increased with the application of ISO.

Our simulation results have shown that our proposed model is useful for exploring the interaction of $\beta$-adrenergic receptor signaling and CaMKII in formation of EADs; some 


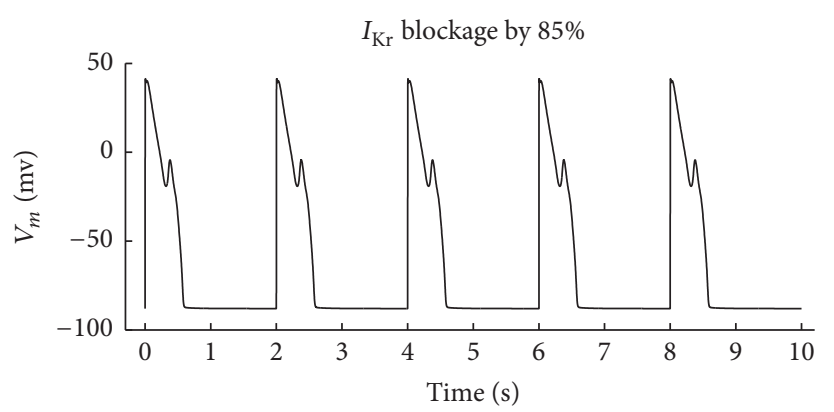

(a)

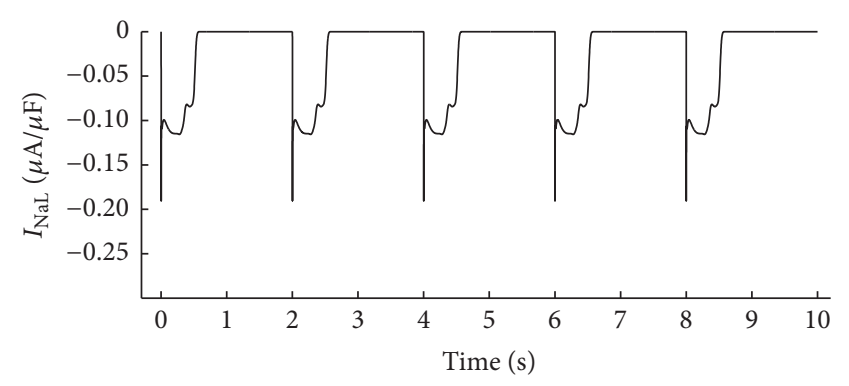

(b)

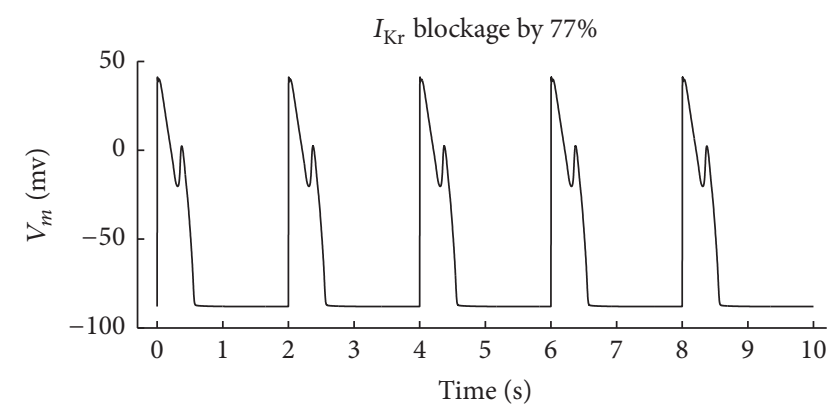

(c)

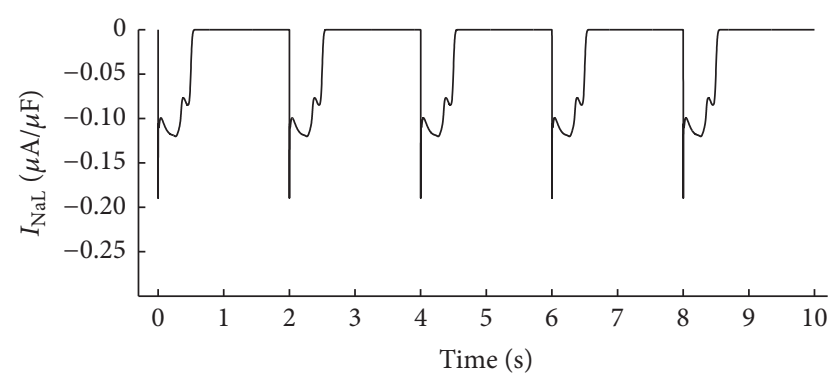

(d)

FIGURE 3: EADs occurred when $I_{\mathrm{Kr}}$ was blocked by $85 \%$ (a) and $77 \%$ (c); corresponding $I_{\mathrm{NaL}}$ when $I_{\mathrm{Kr}}$ was blocked by $85 \%$ (b) and $77 \%$ (d). CL was set $2000 \mathrm{~ms}, 1 \mu \mathrm{M}$ ISO was applied and $\mathrm{CaMK}_{0}$ for $I_{\mathrm{NaL}}$ was set 0.12 independently.

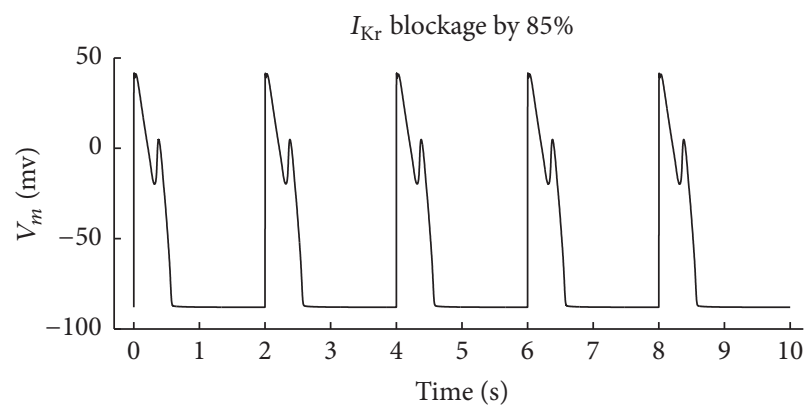

(a)

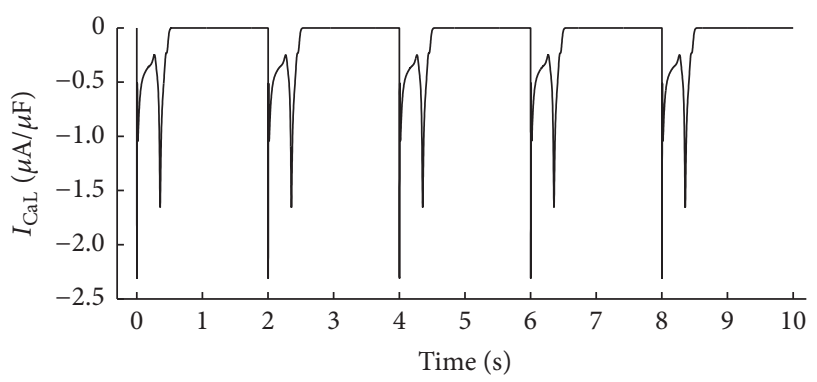

(b)

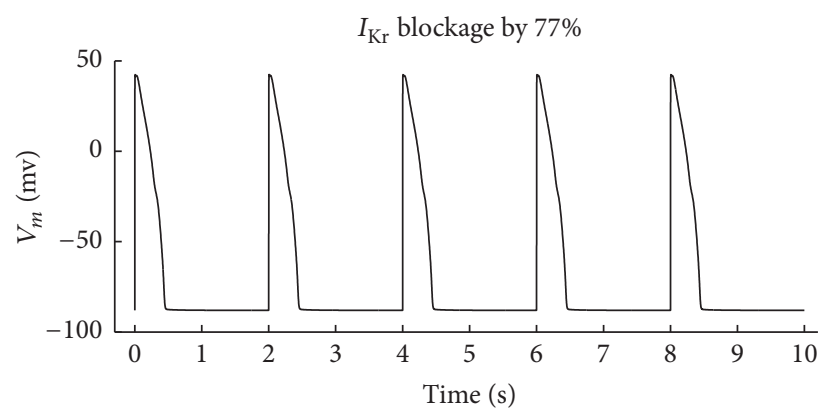

(c)

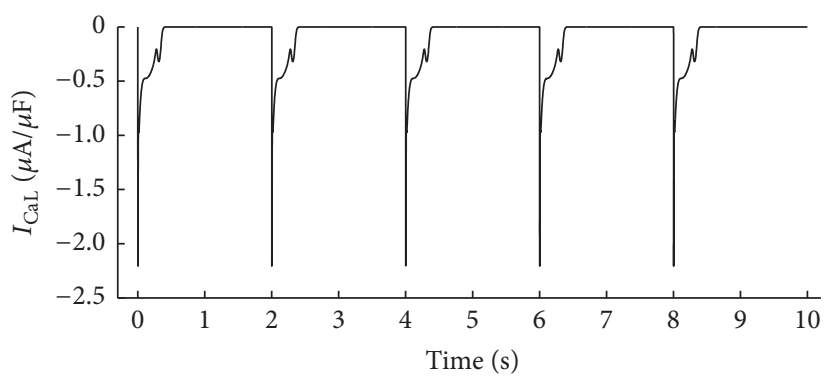

(d)

FIGURE 4: $1 \mu \mathrm{M}$ ISO was applied and cycle length was $2000 \mathrm{~ms}$. $\mathrm{CaMK}_{0}$ for $I_{\mathrm{CaL}}$ was 0.12 but $\mathrm{CaMK}_{0}$ for other targets was 0.05 . EADs occurred when $I_{\mathrm{Kr}}$ was blocked by $85 \%$ in (a), but when $I_{\mathrm{Kr}}$ blockage was reduced to $77 \%$, EADs vanished in (c). (b) $I_{\mathrm{CaL}}$ figures when EADs existed. (d) $I_{\mathrm{CaL}}$ figures when EADs vanished.

potential limitations need to be addressed. Firstly, the role of CaMKII on RyR function has not been considered. There is growing evidence about its role in modulating RyR function. Increasing $\mathrm{Ca}^{2+}$ leak via $\mathrm{RyR}$ would limit SR $\mathrm{Ca}^{2+}$ load and disturb $\mathrm{Ca}^{2+}$ cycling. This should be incorporated into an improved model in a future study. Secondly, CaMKII overexpression may downregulate inward rectifier potassium current $\left(I_{\mathrm{K} 1}\right)$ and increase baseline $I_{\mathrm{K} 1}$ amplitude [30]. We did not include any CaMKII effect on $I_{\mathrm{K} 1}$ in our model. Thirdly, our model only describes the short-term effect of CaMKII 
on different current targets. It has been suggested that shortterm and chronic effects of CaMKII are different [30-33]. Short-term (milliseconds to hours) CaMKII overexpression may slow $I_{\text {to }}$ inactivation and accelerate recovery, but chronic overexpression may downregulate $I_{\text {to,fast }}$ and upregulate $I_{\text {to,slow }}[34]$. Therefore, there is a scope to improve our model by taking chronic effects of CaMKII into consideration in future. Fourthly, there is a lack of an accurate measurement about how ISO regulates $I_{\mathrm{NaK}}$ with dynamic calcium change during the beat cycle, although it has been published by Gao et al. [35] that ISO regulated $\mathrm{I}_{\mathrm{NaK}}$ increased (when calcium is $1.4 \mu \mathrm{M}$ ) or decreased in pump current (when calcium is $0.15 \mu \mathrm{M})$ depending on the intracellular $\mathrm{Ca}^{2+}$ concentrations. In our model the resting calcium concentration was $0.12 \mu \mathrm{M}$ and the peak calcium concentration was $1.1 \mu \mathrm{M}$. Similar to the simulation work of Heijman et al. [26], by simply increasing the pump current from $17 \%$ to $33 \%$, no significant change of $I_{\mathrm{NaK}}$ in triggering EADs (results not shown here) has been observed. However, when the continuous experimental data from human ventricular cells is available, the regulation of ISO on $I_{\mathrm{NaK}}$ could be incorporated into the model to reconfirm this nonsignificant effect. Fifthly, it has been reported that local regulation of cAMP and substrate phosphorylation play important roles in $\beta$-adrenergic receptor signaling $[26,36-38]$, so it could be useful to incorporate local control mechanism in a future study. Lastly, there are four CaMKII isoforms $(\alpha, \beta, \gamma, \delta)$ with different distributions, kinetics, and roles in physiological and pathological adjustments. Until now, these differences have not been fully understood. Developing a model with detailed CaMKII isoforms information could be useful when experiment data are available.

In conclusion, our simulation results computationally demonstrated a better understanding of the combinational effect of CaMKII and ISO stimulus on the occurrence of EADs in human ventricular myocyte, which may provide useful tool to research therapeutic methods for the treatment of arrhythmia.

\section{Competing Interests}

The authors declare that there is no conflict of interests regarding the publication of this paper.

\section{Acknowledgments}

This project is supported by the National Natural Science Foundation of China (61527811).

\section{References}

[1] P. F. Cranefield and R. S. Aronson, Cardiac Arrhythmias: The Role of Triggered Activity and Other Mechanisms, Futura Publishing Company, New York, NY, USA, 1988.

[2] J. N. Weiss, A. Garfinkel, H. S. Karagueuzian, P.-S. Chen, and Z. $\mathrm{Qu}$, "Early afterdepolarizations and cardiac arrhythmias," Heart Rhythm, vol. 7, no. 12, pp. 1891-1899, 2010.

[3] J. Zeng and Y. Rudy, "Early afterdepolarizations in cardiac myocytes: mechanism and rate dependence," Biophysical Journal, vol. 68, no. 3, pp. 949-964, 1995.
[4] C. Antzelevitch, Z.-Q. Sun, Z.-Q. Zhang, and G.-X. Yan, "Cellular and ionic mechanisms underling erythromycin-induced long QT intervals and Torsade de Pointes," Journal of the American College of Cardiology, vol. 28, no. 7, pp. 1836-1848, 1997.

[5] W. Shimizu and C. Antzelevitch, "Sodium channel block with mexiletine is effective in reducing dispersion of repolarization and preventing torsade de pointes in LQT2 and LQT3 models of the long-QT syndrome," Circulation, vol. 96, no. 6, pp. 20382047, 1997.

[6] C. T. January, J. M. Riddle, and J. J. Salata, "A model for early afterdepolarizations: Induction with the $\mathrm{Ca}^{2+}$ channel agonist Bay K 8644," Circulation Research, vol. 62, no. 3, pp. 563-571, 1988.

[7] C. T. January and J. M. Riddle, "Early afterdepolarizations: mechanism of induction and block. A role for L-type Ca2+ current," Circulation Research, vol. 64, no. 5, pp. 977-990, 1989.

[8] R. V. Madhvani, Y. Xie, A. Pantazis et al., "Shaping a new $\mathrm{Ca}^{2+}$ conductance to suppress early afterdepolarizations in cardiac myocytes," The Journal of Physiology, vol. 589, no. 24, pp. 60816092, 2011.

[9] P. J. Mohler and T. J. Hund, "Role of CaMKII in cardiovascular health, disease, and arrhythmia," Heart Rhythm, vol. 8, no. 1, pp. 142-144, 2011.

[10] Y. Wu, J. Temple, R. Zhang et al., "Calmodulin kinase II and arrhythmias in a mouse model of cardiac hypertrophy," Circulation, vol. 106, no. 10, pp. 1288-1293, 2002.

[11] Y. L. Hashambhoy, J. L. Greenstein, and R. L. Winslow, "Role of CaMKII in RyR leak, EC coupling and action potential duration: a computational model," Journal of Molecular and Cellular Cardiology, vol. 49, no. 4, pp. 617-624, 2010.

[12] P. D. Swaminathan, A. Purohit, T. J. Hund, and M. E. Anderson, "Calmodulin-dependent protein kinase II: linking heart failure and arrhythmias," Circulation Research, vol. 110, no. 12, pp. 16611677, 2012.

[13] D. M. Bers, Excitation-Contraction Coupling and Cardiac Contractile Force, Kluwer/Academic Publishers, Boston, Mass, USA, 2nd edition, 2001.

[14] S. C. Verduyn, M. A. Vos, A. P. Gorgels, J. Van der Zande, J. D. M. Leunissen, and H. J. Wellens, "The effect of flunarizine and ryanodine on acquired torsades de pointes arrhythmias in the intact canine heart," Journal of Cardiovascular Electrophysiology, vol. 6, no. 3, pp. 189-200, 1995.

[15] L. Carlsson, L. Drews, and G. Duker, "Rhythm anomalies related to delayed repolarization in vivo: Influence of sarcolemmal $\mathrm{Ca}^{2+}$ entry and intracellular $\mathrm{Ca}^{2+}$ overload," Journal of Pharmacology and Experimental Therapeutics, vol. 279, no. 1, pp. 231-239, 1996.

[16] Z. Song, C. Y. Ko, M. Nivala, J. N. Weiss, and Z. Qu, “Complex darly and delayed afterdepolarization dynamics caused by voltage-calcium coupling in cardiac myocytes," Biophysical Journal, vol. 108, no. 8, pp. 261A-262A, 2015.

[17] P. G. A. Volders, A. Kulcsár, M. A. Vos et al., "Similarities between early and delayed afterdepolarizations induced by isoproterenol in canine ventricular myocytes," Cardiovascular Research, vol. 34, no. 2, pp. 348-359, 1997.

[18] C. T. January and H. A. Fozzard, "Delayed afterdepolarizations in heart muscle: mechanisms and relevance," Pharmacological Reviews, vol. 40, no. 3, pp. 219-227, 1988.

[19] Y. Xie, E. Grandi, J. L. Puglisi, D. Sato, and D. M. Bers, " $\beta$-Adrenergic stimulation activates early afterdepolarizations 
transiently via kinetic mismatch of PKA targets," Journal of Molecular and Cellular Cardiology, vol. 58, no. 1, pp. 153-161, 2013.

[20] T. O’Hara, L. Virág, A. Varró, and Y. Rudy, "Simulation of the undiseased human cardiac ventricular action potential: model formulation and experimental validation," PLoS Computational Biology, vol. 7, no. 5, Article ID e1002061, 2011.

[21] K. F. Decker, J. Heijman, J. R. Silva, T. J. Hund, and Y. Rudy, "Properties and ionic mechanisms of action potential adaptation, restitution, and accommodation in canine epicardium," American Journal of Physiology - Heart and Circulatory Physiology, vol. 296, no. 4, pp. H1017-H1026, 2009.

[22] T. J. Hund and Y. Rudy, "Rate dependence and regulation of action potential and calcium transient in a canine cardiac ventricular cell model," Circulation, vol. 110, no. 20, pp. 31683174, 2004.

[23] M. Kohlhaas, T. Zhang, T. Seidler et al., "Increased sarcoplasmic reticulum calcium leak but unaltered contractility by acute CaMKII overexpression in isolated rabbit cardiac myocytes," Circulation Research, vol. 98, no. 2, pp. 235-244, 2006.

[24] A. R. Soltis and J. J. Saucerman, "Synergy between CaMKII substrates and $\beta$-adrenergic signaling in regulation of cardiac myocyte $\mathrm{Ca}^{2+}$ handling," Biophysical Journal, vol. 99, no. 7, pp. 2038-2047, 2010.

[25] M. J. Lohse, S. Engelhardt, and T. Eschenhagen, "What is the role of $\beta$-adrenergic signaling in heart failure?" Circulation Research, vol. 93, no. 10, pp. 896-906, 2003.

[26] J. Heijman, P. G. A. Volders, R. L. Westra, and Y. Rudy, "Local control of $\beta$-adrenergic stimulation: effects on ventricular myocyte electrophysiology and $\mathrm{Ca}^{2+}$-transient," Journal of Molecular and Cellular Cardiology, vol. 50, no. 5, pp. 863-871, 2011.

[27] D. Guo, Q. Liu, T. Liu et al., "Electrophysiological properties of HBI-3000: a new antiarrhythmic agent with multiple-channel blocking properties in human ventricular myocytes," Journal of Cardiovascular Pharmacology, vol. 57, no. 1, pp. 79-85, 2011.

[28] A. Zaza, L. Belardinelli, and J. C. Shryock, "Pathophysiology and pharmacology of the cardiac 'late sodium current," Pharmacology and Therapeutics, vol. 119, no. 3, pp. 326-339, 2008.

[29] P. G. A. Volders, M. Stengl, J. M. Van Opstal et al., "Probing the contribution of IKs to canine ventricular repolarization: key role for $\beta$-adrenergic receptor stimulation," Circulation, vol. 107, no. 21, pp. 2753-2760, 2003.

[30] S. Wagner, E. Hacker, E. Grandi et al., "Ca/calmodulin kinase II differentially modulates potassium currents," Circulation: Arrhythmia and Electrophysiology, vol. 2, no. 3, pp. 285-294, 2009.

[31] S. Tessier, P. Karczewski, E.-G. Krause et al., "Regulation of the transient outward $\mathrm{K}+$ current by $\mathrm{Ca} 2+/$ calmodulin- dependent protein kinases II in human atrial myocytes," Circulation Research, vol. 85, no. 9, pp. 810-819, 1999.

[32] O. Colinas, M. Gallego, R. Setién, J. R. López-López, M. T. Pérez-García, and O. Casis, "Differential modulation of Kv4.2 and Kv4.3 channels by calmodulin-dependent protein kinase II in rat cardiac myocytes," American Journal of Physiology-Heart and Circulatory Physiology, vol. 291, no. 4, pp. H1978-H1987, 2006.

[33] G. P. Sergeant, S. Ohya, J. A. Reihill et al., "Regulation of $\mathrm{K}_{\mathrm{v}} 4.3$ currents by $\mathrm{Ca}^{2+} /$ calmodulin-dependent protein kinase II," American Journal of Physiology-Cell Physiology, vol. 288, no. 2, pp. C304-C313, 2005.
[34] M. E. Anderson, J. H. Brown, and D. M. Bers, "CaMKII in myocardial hypertrophy and heart failure," Journal of Molecular and Cellular Cardiology, vol. 51, no. 4, pp. 468-473, 2011.

[35] J. Gao, R. Wymore, R. T. Wymore et al., "Isoform-specific regulation of the sodium pump by $\alpha$-and $\beta$-adrenergic agonists in the guinea-pig ventricle," The Journal of Physiology, vol. 516, no. 2, pp. 377-383, 1999.

[36] V. O. Nikolaev, A. Moshkov, A. R. Lyon et al., “ $\beta_{2}$-Adrenergic receptor redistribution in heart failure changes cAMP compartmentation," Science, vol. 327, no. 5973, pp. 1653-1657, 2010.

[37] P. T. Wright, V. O. Nikolaev, T. O’Hara et al., "Caveolin-3 regulates compartmentation of cardiomyocyte beta2-adrenergic receptor-mediated cAMP signaling," Journal of Molecular and Cellular Cardiology, vol. 67, pp. 38-48, 2014.

[38] R. V. Iancu, S. W. Jones, and R. D. Harvey, "Compartmentation of cAMP signaling in cardiac myocytes: a computational study," Biophysical Journal, vol. 92, no. 9, pp. 3317-3331, 2007. 


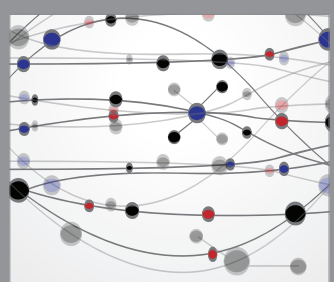

The Scientific World Journal
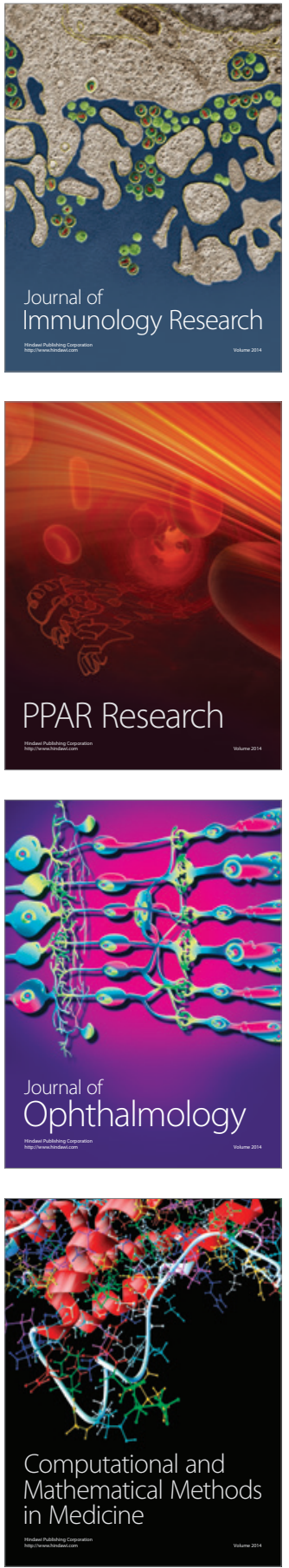

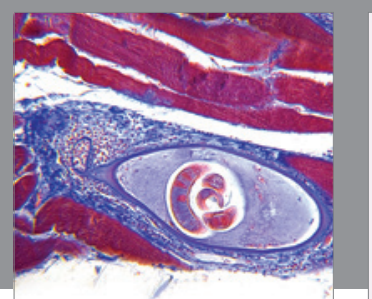

Gastroenterology Research and Practice

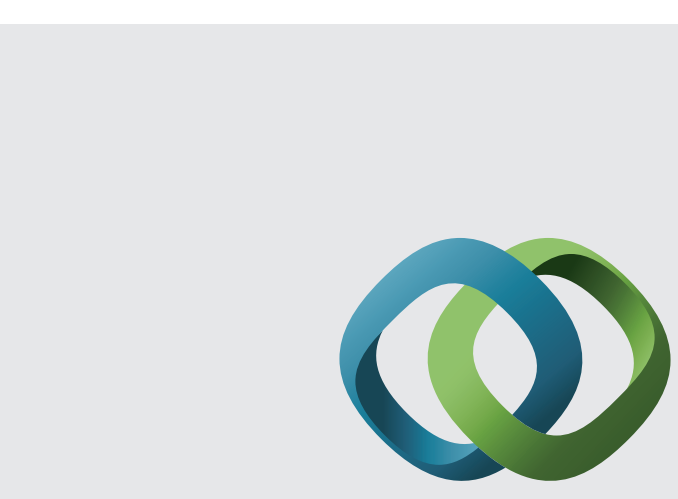

\section{Hindawi}

Submit your manuscripts at

http://www.hindawi.com
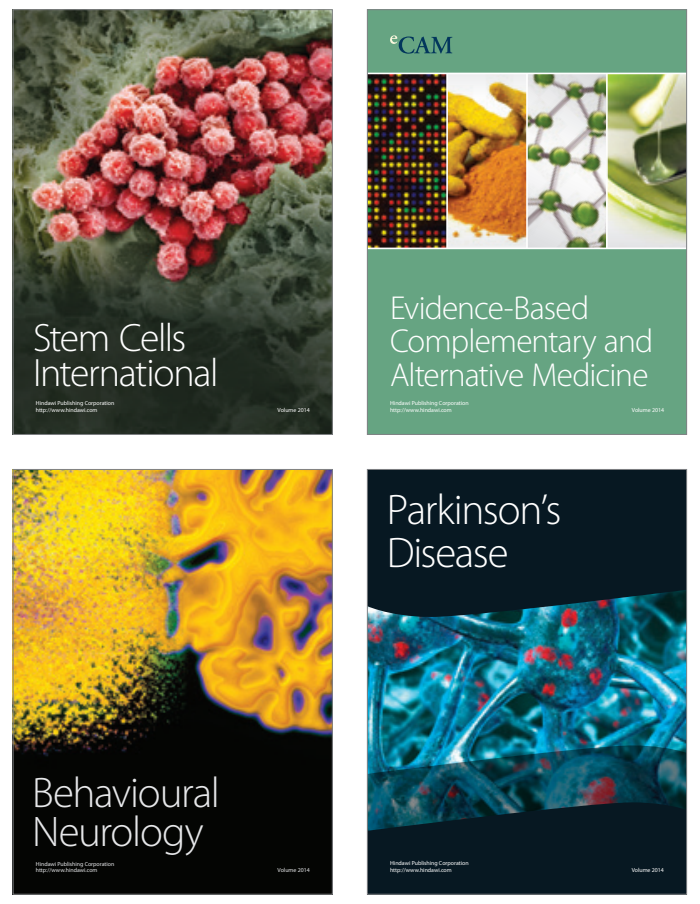
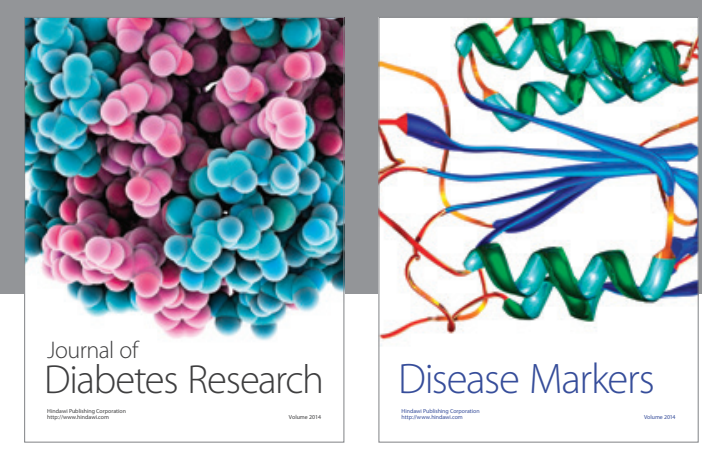

Disease Markers
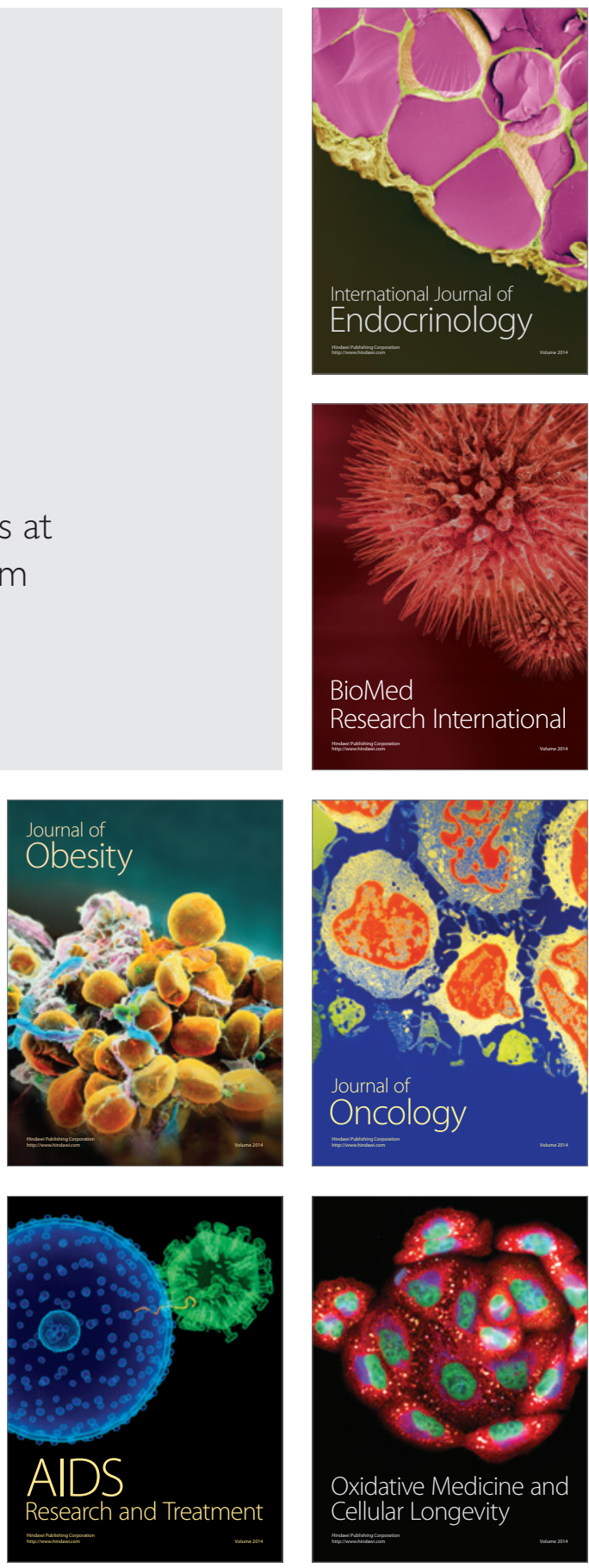